\title{
Effects of the 4C Core Competencies on Work Ability among Dental Hygienists
}

\author{
Do-Young Kim and Kyeung-Ae Jang ${ }^{\dagger}$ \\ Department of Dental Hygiene, College of Health and Welfare, Silla University, Busan 46958, Korea
}

\begin{abstract}
Background: This descriptive study aimed to examine the relationship between the $4 \mathrm{C}$ core competencies and work ability among dental hygienists.

Methods: From November 2018 to January 2019, data were collected-from 190 dental hygienists workong in dental clinics in Busan, Ulsan, and Gyeongsangnam province using structured questionnaires. For the general characteristics of the dental hygienists, frequency and percentage were calculated, and the level of the $4 \mathrm{C}$ core competencies and work ability of dental hygienists was calculated using means and standard deviations. A multiple regression analysis was conducted to analyze the effects of the $4 \mathrm{C}$ core competencies on work ability.

Results: The mean scores for the $4 \mathrm{C}$ core competency levels of the dental hygienists were as follows: communication ability 3.34 , critical thinking ability 3.41, creative problem-solving 3.40, and collaborative self-efficacy 3.27. Meanwhile the mean score for work ability level was 3.65. The predictive factors influencing work ability were communication ability and cooperative self-efficacy $(p<0.001)$, and the sub-factors of critical thinking ability that affect work ability were sound conferences $(p<0.01)$, intellectual fairness $(p<0.05)$, intellectual enthusiasm $(p<0.05)$, and self-confidence $(p<0.001)$. Finally, the sub-factors of creative problem-solving ability that affect work ability were planning and execution $(p<0.01)$ and performance evaluation $(p<0.05)$. Conclusion: The current study showed that education programs covering the core competencies of dental hygienists, rather than the existing theoretical education program, should be developed and implemented to enhance $4 \mathrm{C}$ core competencies that affect work ability.
\end{abstract}

Key Words: Ability, Communication, Critical thinking, Problem solving, Self-efficacy

\section{Introduction}

In recent years, as the education level of patients has increased and information acquisition has become easier ${ }^{1}$, knowledge and awareness of medical care have increased and awareness of patients' rights and rights to selfdetermination has been strengthened ${ }^{2}$. Furthermore, as patient participation has increased, communication with patients has expected to become increasingly important, and preparation is required to develop work ability to actively accept and respond to the changing environment of dental clinical treatment caused by the Fourth Industrial Revolution.
Work ability refers to the ability to perform work proficiently using appropriate knowledge, decisions, and clinically required skills ${ }^{3)}$, and as the social demand for dental hygienists has changed, the scope of their work ability has expanded from cooperative work using simple knowledge and skills to prevention, education, interpersonal skills, and serving as a business thus ${ }^{4}$. Core competencies that suit the current trend are required to develop work abilities in preparation for the future society. Among the numerous competencies, communication ability, critical thinking ability, creative problem-solving ability, and collaborative self-efficacy have been considered the $4 \mathrm{C}$ core competencies required for the Fourth Industrial 
Revolution" ${ }^{5)}$.

Communication is a complex action of delivering one's own message and receiving another's to mutually exchange one's thoughts and feelings with one's interlocutor ${ }^{6}$, and the communication ability of dental hygienist affects organizational effectiveness ${ }^{7)}$.

Critical thinking refers to making the best decision by understanding the logical structure and meaning of information and considering evidence and methods in determining whether to accept a certain opinion and to take a certain action $^{8)}$. A significant positive correlation was observed between critical thinking ability and problem-solving ability as well as job performance among dental hygienists ${ }^{9)}$, and when critical thinking propensity is high in the nursing domain, a decision can be made quickly and efficiently in a high-risk situation relevant to clinical competence and patient safety $^{10)}$.

Creative problem-solving refers to a creative and intelligent ability to recognize the difference between one's current state and goals and to address this gap ${ }^{11)}$. When a difficult situation related to the safety of patients is encounterd, problem-solving ability is required to quickly identify and solve problems ${ }^{10)}$.

Collaborative self-efficacy refers to the belief of an individual learner that he/she can perform a team project successfully and contribute to a collaborative activity ${ }^{12)}$. As self-efficacy increases, one sets high work-related goals and endeavors proactively to achieve self-efficacy, thereby affecting organizational commitment ${ }^{13)}$.

A previous study has found that communication, critical thinking, creative problem-solving, and collaborative selfefficacy are significant for dental hygienists, However, no study has assessed the effects of the $4 \mathrm{C}$ core competencies on work ability.

Therefore, this study aimed to investigate the effects of the $4 \mathrm{C}$ core competencies on work ability among dental hygienists. Furthermore, we assessed whether problemsolving-oriented participatory educational programs based on the $4 \mathrm{C}$ core competencies rather than the conventional theoretical education, should be developed developed to enhance the work abilities of dental hygienists which is required in the Fourth Industrial Revolution.

\section{Materials and Methods}

\section{Study participants}

The study was conducted from November 2018 to January 2019. Of the 200 copies of the survey questionnaire that were distributed, 190 with honest responses were honestly answered were collected and analyzed. The study participants were dental hygienists working in dental clinics and general hospitals located in Gyeongsangnam province, Ulsan, and Busan, and a structured survey targeting 200 respondents was conducted after the objectives of the study were explained and consent was obtained. Using $\mathrm{G}^{*}$ power 3.1.3 based on Cohen's power analysis, a minimum sample size of 181 was required under the following conditions: 5\% (both sides) significance level, $80 \%$ power, and 0.15 effect size. However, considering the possible drop-out rate, the survey included a total sample size of 200 .

\section{Study methods}

\section{1) Communication ability}

A tool developed by Lee ${ }^{14)}$ was used to measure the variables of communication ability. A total of 49 questions was developed for the following sub-factors: used. A total of 49 questions were developed under five sub-factors: solving ability, role-performing ability, self-presentation ability, goal setting ability, and message transition ability. Each question was scored on a 5-point Likert scale, and a high score indicated that the participants had a high level of communication ability. For communication ability, the Cronbach's alpha value was 0.84 .

\section{2) Critical thinking ability}

A tool developed by Yoon ${ }^{15)}$ was used to measure the variables of critical thinking ability. A total of 27 questions was developed for the following sub-factors: healthy skepticism, intellectual fairness, objectivity, systematicity, prudence, intellectual passion, and self-confidence. Each question was scored on a 5-point Likert scale, and a high score indicated that the participants had a high level of critical thinking ability. For critical thinking ability, the Cronbach's alpha value was 0.91 . 


\section{3) Creative problem-solving ability}

A tool developed by Lee ${ }^{14)}$ was used to measure the variables of creative problem-solving ability. A total of 45 questions was developed for the following sub-factors: problem clarification, causal analysis, development of alternatives, planning and execution, and performance evaluation. Each question was scored on a 5-point Likert scale, and a high score indicated that the participants had a high level of creative problem-solving ability. For creative problem-solving ability, the Cronbach's alpha value was 0.94 .

\section{4) Collaborative self-efficacy}

A tool developed by Alavi and McCormick ${ }^{16)}$ was used to measure the variables of collaborative self-efficacy. A total of 19 questions was developed for the following subfactors: opinion consolidation, opinion assessment, opinion exchange, and exhibition of leadership. Each question was scored on a 5-point Likert scale, and a high score indicated that the participants had a high collaborative self-efficacy. For collaborative self-efficacy, the Cronbach's alpha value was 0.94 .

\section{5) Work ability}

A tool developed and modified by Kim and Hwang ${ }^{17)}$ and $\mathrm{Kim}$ and $\mathrm{Han}^{18)}$ was used to measure the variables of work ability. A total of 26 questions was developed for the

Table 1. General Characteristics $(n=190)$

\begin{tabular}{llr}
\hline \multicolumn{1}{c}{ Classification } & \multicolumn{1}{c}{ Category } & $\mathrm{n}(\%)$ \\
\hline Age (y) & $\leq 25$ & $91(47.9)$ \\
& $26 \sim 29$ & $43(22.6)$ \\
& $\geq 30$ & $56(29.5)$ \\
Marital ststus & Single & $137(72.1)$ \\
& Married & $53(27.9)$ \\
Workplace type & Dental clinic & $100(52.6)$ \\
& Dental hospital & $88(46.3)$ \\
& General hospital & $2(1.1)$ \\
Job position & Regular dental hygienist & $134(70.5)$ \\
& Mid-level manager & $36(18.9)$ \\
& Senior manager & $15(7.9)$ \\
& Others & $5(2.6)$ \\
Clinical experience & $<5 y e a r$ & $100(52.6)$ \\
& 5 9 year & $51(26.8)$ \\
& $\geq 10$ year & $39(20.5)$ \\
\hline
\end{tabular}

following sub-factors, ability and attitude. Each question was scored on a 5-point Likert scale, and a high score indicated that the participants had a high level of work ability. For work ability, the Cronbach's alpha value was 0.96 .

\section{Data analysis}

The data collected in this study were analyzed using the SPSS software version 25.0 (IBM Corp., Armonk, NY, USA) and were tested at a significance level of 0.05 . For

Table 2. 4C Core Competence and Work Level of Dental Hygienists $(n=190)$

\begin{tabular}{|c|c|c|}
\hline Classification & Category & $\begin{array}{c}\text { Mean } \pm \text { standard } \\
\text { deviation }\end{array}$ \\
\hline \multirow{6}{*}{$\begin{array}{l}\text { Communication } \\
\text { ability }\end{array}$} & Interpreting Ability & $3.50 \pm 0.35$ \\
\hline & Ability to perform roles & $3.46 \pm 0.38$ \\
\hline & Self-presentation ability & $3.29 \pm 0.52$ \\
\hline & Ability to set goals & $3.04 \pm 0.63$ \\
\hline & Message conversion ability & $3.39 \pm 0.59$ \\
\hline & Total & $3.34 \pm 0.33$ \\
\hline \multirow[t]{8}{*}{ Critical thinking } & Sound skepticism & $3.40 \pm 0.65$ \\
\hline & Intellectual fairness & $3.58 \pm 0.60$ \\
\hline & Objectivity & $3.79 \pm 0.67$ \\
\hline & Systemicity & $2.99 \pm 0.77$ \\
\hline & Prudence & $3.50 \pm 0.74$ \\
\hline & Intellectual passion & $3.31 \pm 0.70$ \\
\hline & Confidence & $3.28 \pm 0.70$ \\
\hline & Total & $3.41 \pm 0.46$ \\
\hline \multirow{6}{*}{$\begin{array}{l}\text { Creative } \\
\text { problem-solving }\end{array}$} & Clarification of problem & $3.47 \pm 0.54$ \\
\hline & Cause analysis & $3.40 \pm 0.39$ \\
\hline & Alternative development & $3.39 \pm 0.49$ \\
\hline & Planning & $3.28 \pm 0.57$ \\
\hline & Performance evaluation & $3.45 \pm 0.54$ \\
\hline & Total & $3.40 \pm 0.41$ \\
\hline \multirow{5}{*}{$\begin{array}{l}\text { Collaborative } \\
\text { self-efficacy }\end{array}$} & Opinion integration & $3.22 \pm 0.61$ \\
\hline & Opinion evaluation & $3.20 \pm 0.69$ \\
\hline & Opinion exchange & $3.42 \pm 0.59$ \\
\hline & Exerting leadership & $3.24 \pm 0.64$ \\
\hline & Total & $3.27 \pm 0.54$ \\
\hline \multicolumn{3}{|l|}{ Work ability } \\
\hline \multirow[t]{4}{*}{ Ability } & Professionalism & $3.41 \pm 0.63$ \\
\hline & Creativity & $3.35 \pm 0.67$ \\
\hline & Understanding judgment & $3.67 \pm 0.69$ \\
\hline & Total & $3.48 \pm 0.60$ \\
\hline \multirow[t]{4}{*}{ Attitude } & Cooperation & $3.58 \pm 0.68$ \\
\hline & Work & $3.95 \pm 0.70$ \\
\hline & Customer orientation & $3.91 \pm 0.65$ \\
\hline & Total & $3.81 \pm 0.60$ \\
\hline Total & & $3.65 \pm 0.56$ \\
\hline
\end{tabular}


the general characteristics of the dental hygienists, frequency and percentage were calculated, and the level of the $4 \mathrm{C}$ core competencies and work ability of the dental hygienists were calculated using means and standard deviations. A multiple regression analysis was conducted to analyze the effects of the $4 \mathrm{C}$ core competencies on work ability.

\section{Results}

\section{General characteristics of the participants}

Table 1 shows the general characteristics of the study participants. The age groups were as follows: 25 years (47.9\%), 30 years $(29.5 \%)$, and $26 \sim 29$ years $(22.6 \%)$. Moreover, $27.9 \%$ of the participants were married, whereas $72.1 \%$ were not. The types of workplace were dental clinics $(52.6 \%)$, dental hospitals $(46.3 \%)$, and general hospitals $(1.1 \%)$. In terms of job positions, regular dental hygienists $(70.5 \%)$ had, the highest proportion, followed by mid-level managers $(18.9 \%)$, senior managers $(7.9 \%)$, and other types of jobs $(2.6 \%)$. Regarding clinical experience, participants with $<5$ years of experience $(52.6 \%)$ had the highest proportion, followed by those with $5 \sim 9$ years $(26.8 \%)$ and $\geq 10$ years of experience $(20.5 \%)$.

\section{4C core competency and work ability levels of dental hygienists}

Table 2 depicts the 4C core competency and work ability levels of dental hygienists. The mean scores for the $4 \mathrm{C}$ core competency levels of the dental hygienists were as follows: communication ability 3.34, critical thinking ability 3.41 , creative problem-solving ability 3.40, and collaborative self-efficacy 3.27. Meanwhile, the mean score for work ability level was 3.65. Among the sub-factors of communication ability, interpretation ability had, the highest score at 3.50, and among the sub-factors of critical thinking ability, objectivity had scored the highest score at, 3.79 points. And among the sub-factors of creative problem-solving ability, problem clarification had the highest score at 3.47 points, and among the sub-factors of collaborative self-efficacy, both opinion exchange and leadership exhibition had the highest scores at 3.42. Regarding the sub-factors of work ability, the scores for attitude and ability were 3.81 and 3.48 , respectively. Regarding the sub-factors of attitude, the score for work attitude was 3.95, and among the sub-factors of ability, understanding and judgment had the highest score at 3.67 points.

opinion exchange and leadership exhibition both received 3.42 points, the highest score. Among the sub-factors of work ability, attitude and ability showed 3.81 points and 3.48 points, respectively. Among the sub-factors of attitude, work attitude scored 3.95 points, while among the sub-factors of ability, understanding and judgment showed the highest score of 3.67 points.

\section{Factors of the $4 \mathrm{C}$ competencies affecting work ability}

Table 3 shows the factors of the $4 \mathrm{C}$ core competencies affecting work ability. The linear regression model showed

Table 3. Factors of 4C Core Competence Affecting Work Ability

\begin{tabular}{|c|c|c|c|c|c|c|}
\hline \multirow{2}{*}{ Independence variable } & \multicolumn{3}{|c|}{ Dependence variable } & \multirow{2}{*}{$\mathrm{t}$} & \multirow{2}{*}{ p-value } & \multirow{2}{*}{ VIF } \\
\hline & $\mathrm{B}$ & $\mathrm{SE}$ & $\operatorname{EXP}(\beta)$ & & & \\
\hline \multicolumn{7}{|l|}{ 4C core competence } \\
\hline Constant & 0.106 & 0.314 & & 0.338 & & \\
\hline Communication ability & 0.524 & 0.116 & 0.313 & 4.515 & $<0.001$ & 1.665 \\
\hline Critical thinking ability & 0.141 & 0.108 & 0.117 & 1.299 & 0.196 & 2.811 \\
\hline Creative problem-solving ability & 0.051 & 0.118 & 0.038 & 0.430 & 0.668 & 2.654 \\
\hline Collaborative self-efficacy & 0.348 & 0.076 & 0.339 & 4.578 & $<0.001$ & 1.905 \\
\hline
\end{tabular}

$\mathrm{R}^{2}=0.466$, adjusted $\mathrm{R}^{2}=0.454, \mathrm{~F}=40.343, \mathrm{p}<0.001$, Durbin-Watson=1.711

The data were analysed by the multiple regression analysis.

Do not show variables that are not statistically significant $(\mathrm{p}>0.05)$.

VIF: variance inflation factor. 
a significant relationship between the factors and work ability $(\mathrm{F}=40.343, \mathrm{p}<0.001)$, with an explanatory power of $45.4 \%$. The significant predictive factors of work ability were communication ability $(\mathrm{t}=4.515, \mathrm{p}<0.001)$ and collaborative self-efficacy $(\mathrm{t}=4.578, \mathrm{p}<0.001)$.

\section{Influence of the $4 \mathrm{C}$ core competency factors on work ability}

Table 4 shows the influence of the $4 \mathrm{C}$ core competencies factors on work ability. The linear regression model showed a significant relationship between the factors and work ability $(\mathrm{F}=17.812, \mathrm{p}<0.001)$, with an explanatory power of $47.1 \%$. The significant predictive factors of work ability were opinion exchange $(\mathrm{t}=4.063, \mathrm{p}<$ $0.001)$, confidence $(\mathrm{t}=2.233, \mathrm{p}<0.05)$, sound skepticism $(\mathrm{t}=1.932, \mathrm{p}<0.01)$, and ability to perform roles $(\mathrm{t}=2.460$, $\mathrm{p}<0.05)$.

\section{Discussion}

Dental hygienists should accept changes and respond to novel situations to prepare for future dental care workplaces in the Fourth Industrial Revolution ${ }^{19)}$. Competencies must be developed to ensure the work abilities required in the
Fourth Industrial Revolution, and among the 4C core competencies, communication ability, critical thinking ability, creative problem-solving ability, and collaborative self-efficacy are important. Therefore, the current study investigated the effects of the $4 \mathrm{C}$ core competencies on work ability among dental hygienists.

In terms of the $4 \mathrm{C}$ core competencies of the dental hygienists, the average score for communication ability was 3.34, and among the sub-factors of communication ability, interpretation ability had the highest average score, followed by role-performing ability, message-transition ability, self-presentation ability, and goal-setting ability. Interpretation ability conveys meaning through communication that suits the interlocutor's environment ${ }^{14)}$. Moreover, because dental hygienists listen and pay attention to the patients when performing their work, the average score for interpretation ability is high ${ }^{7)}$. The communication ability of dental hygienists is an important competency required to perform the role of mid-level managers. To improve the communication ability of dental hygienists, learners should establish a team and devise solutions for existing problems within a given time and implement them on their own, which results to sharing experiences. Thus, the level of communication ability is increased through interactions

Table 4. Influence of $4 \mathrm{C}$ Core Compentence Item Factors on Work Ability

\begin{tabular}{|c|c|c|c|c|c|c|}
\hline \multirow{2}{*}{ Independence variable } & \multicolumn{3}{|c|}{ Dependence variable } & \multirow{2}{*}{$\mathrm{t}$} & \multirow{2}{*}{$\mathrm{p}$-value } & \multirow{2}{*}{ VIF } \\
\hline & $\mathrm{B}$ & $\mathrm{SE}$ & $\operatorname{EXP}(\beta)$ & & & \\
\hline \multicolumn{7}{|l|}{ 4C core competence } \\
\hline Constant & 0.349 & 0.347 & & 1.006 & 0.316 & \\
\hline Ability to perform roles & 0.205 & 0.083 & 0.139 & 2.460 & 0.015 & 11.14 \\
\hline Ability to set goals & 0.108 & 0.060 & 0.122 & 1.792 & 0.075 & 1.64 \\
\hline Message conversion ability & 0.102 & 0.065 & 0.108 & 1.577 & 0.116 & 1.67 \\
\hline Sound skepticism & 0.098 & 0.051 & 0.114 & 1.932 & 0.055 & 1.23 \\
\hline Intellectual fairness & 0.094 & 0.059 & 0.100 & 1.593 & 0.113 & 1.41 \\
\hline Intellectual passion & 0.071 & 0.058 & 0.090 & 1.238 & 0.217 & 1.86 \\
\hline Confidence & 0.128 & 0.057 & 0.161 & 2.233 & 0.027 & 1.85 \\
\hline Planning & 0.072 & 0.790 & 0.730 & 0.901 & 0.369 & 2.33 \\
\hline Performance evaluation & 0.042 & 0.086 & 0.041 & 0.492 & 0.623 & 2.52 \\
\hline Opinion exchange & 0.255 & 0.063 & 0.271 & 4.063 & $<0.001$ & 1.58 \\
\hline
\end{tabular}

$\mathrm{R}^{2}=0.499$, adjusted $\mathrm{R}^{2}=0.471, \mathrm{~F}=17.812, \mathrm{p}<0.001$, Durbin-Watson=1.706

The data were analysed by the multiple regression analysis.

Do not show variables that are not statistically significant $(\mathrm{p}>0.05)$.

VIF: variance inflation factor. 
with colleagues when collecting, analyzing, and using data to solve a problem ${ }^{20)}$.

The average score for critical thinking ability was 3.41 , and among its sub-factors, objectivity had the highest average score, followed by intellectual fairness, prudence, healthy skepticism, intellectual passion, self-confidence, and systematicity. Yoo et al. ${ }^{21)}$ has reported that propensity for objectivity in problem-solving is required when a nurse encounters a challenging situation. Similarly, dental hygienists may solve problems based on valid grounds. Because critical thinking ability affects fast and efficient decision-making, it is considered crucial for dental hygienists who deal with changing medical environments and a variety of patients.

Similarly, the average score for creative problemsolving ability was 3.40 , and among its sub-factors, problem clarification had the highest score, followed by performance evaluation, causal analysis, alternative development, and planning and execution. Kim and $\operatorname{Han}^{10)}$ have shown that the problem-solving abilities of nurses affect the improvement of their critical thinking for fast and efficient decision-making. Accordingly, improvement in the creative problem-solving abilities of dental hygienists has positive effects on critical thinking ability.

Moreover, the average score for collaborative selfefficacy was 3.27, and among its sub-factors, opinion exchange had the highest score, followed by leadership exhibition, opinion consolidation, and opinion assessment. Cho and $\mathrm{Moon}^{22)}$ and Kim et al. ${ }^{23)}$ have shown that self-efficacy affects job satisfaction and organizational commitment. As the level of job satisfaction and organizational commitment increases, the level of work ability also increases, which in turn can yield high-quality medical services for patients and can positively affect the medical service satisfaction of patients.

The average score for work ability was 3.65 , and among its sub-factors, the average scores for attitude and ability were 3.65 and 3.48. In a previous study that has investigated the effect of self-leadership on organizational effectiveness and work ability among dental hygienists ${ }^{18)}$, the average score for work ability is 3.70 , and in terms of its sub-factors, the average scores for attitude and ability are 3.88 and 3.46 points, respectively. These results are similar to those of the current study. Among the sub-factors of attitude, work attitude had the highest average score, followed by customer orientation and cooperation, and among the sub-factors of ability, understanding and judgment had the highest average score, followed by expertise and creativity. The score was higher for attitude than for ability because the research tool was selfadministered and the subjective evaluation of ability was more difficult than that of attitude. Furthermore, dental hygienists should develop their work ability while coping up with changes because the scope and role of work ability expand with social change.

The factors of the $4 \mathrm{C}$ core competencies of dental hygienists that affect work ability were communication ability $(\mathrm{p}<0.001)$ and collaborative self-efficacy $(\mathrm{p}<$ 0.001). Although critical thinking ability and creative problem-solving ability did not affect work ability, the sub-factors of each affected work ability. To improve the work ability of dental hygienists, it should be applied to communicative workplace training and seminars based on participatory education programs. A program is also required for experienced educators in the workplace.

The present study had some limitations. That is, the results cannot be generalized because the study was conducted on dental hygienists in Busan, Ulsan, and Gyeongsangnam province. Moreover, because no previous study has specifically investigated the relationship between the $4 \mathrm{C}$ core competencies and work ability among dental hygienists, it was difficult to objectively compare and explain the results of the current study. Therefore, a follow-up research must be conducted to expand the research targets and regions and to investigate the development process of educational programs and effective educational methods that can improve the respective factors.

Hence, the 4C core competencies were important factors that affect the development of the work ability of dental hygienists. Programs that can be applied to trainings at work, refresher trainings, and seminars should be developed in the form of problem-solving-oriented participatory education, which can increase the level of the $4 \mathrm{C}$ core competencies, rather than conventional theoretical education. As a result, the work ability of dental hygienists 
will improve, and they can then deal with changes in the medical environment caused by the Fourth Industrial Revolution.

\section{Notes}

\section{Conflict of interest}

No potential conflict of interest relevant to this article was reported.

\section{Ethical approval}

This study was approved by the institutional review board of Silla University (IRB No. 1041449-201810HR-002).

\section{ORCID}

Do-Young Kim, https://orcid.org/0000-0003-3496-6105

Kyeung-Ae Jang, https://orcid.org/0000-0001-7903-7866

\section{References}

1. Greaves D, Evans M: Medical humanities. Med Humanit 26: 1-2, 2000. https://doi.org/10.1136/mh.26.1.1

2. So YR, Baik BJ, Kim JG, Yang YM, Lee YH: The attitude survey of orthodontic patients' parents at Chonbuk National University Hospital, the department of pediatric dentistry. J Korean Acad Pediatr Dent 35: 487-493, 2008.

3. Barrett C, Myrick F: Job satisfaction in preceptorship and its effect on the clinical performance of the preceptee. J Adv Nurs 27: 364-371, 1998. https://doi.org/10.1046/j.1365-2648.1998.00511.x

4. Ryu HG: The correlation between the internal - external satisfaction and organizational commitment of dental hygienist. J Korean Soc Dent Hyg 17: 735-745, 2017.

5. Beers SZ. Teaching 21th century skills: an ASCD action tool. Academy Press, Seoul, pp.20-24, 2017.

6. Jo HI, Lee MH: The mediating effect of prosocial behavior in the relation between empathic ability and psychological well-being. Korean J Youth Stud 17: 139-158, 2010.

7. Gown AR, Han SJ: Effect of communication competence on the organizational effectiveness in dental hygienists. J Korean Soc Dent Hyg 15: 1009-1017, 2015. https://doi.org/10.13065/jksdh.2015.15.06.1009
8. Kim MS: Issues and direction of critical thinking education in elementary and secondary education. J Soc Philosophical Stud 58: 107-144, 2002.

9. Lee JE, Lee SY, Kim HJ: The effects of critical thinking disposition and problem solving ability on the work performance assessment of dental hygienists. J Dent Hyg Sci 17: 275-282, 2017. https://doi.org/10.17135/jdhs.2017.17.4.275

10. Kim HS, Han SJ: The survey on the influence of clinical nurse's critical thinking disposition, problem-solving skill and self-efficacy on patients safety competencies. J Korea Acad-Ind Cooper Soc 17: 598-608, 2016. http://doi.org/10.5762/KAIS.2016.17.6.598

11. Choi EY, Kim JY: The relationship of core competencies (problem solving ability, communication ability, self-directed learning ability) to critical thinking. Korean J Fundam Nurs 14: 412-419, 2007.

12. Lim KY, Kim SW, Kim YJ: The relationships between metacognitive self-regulation, emotion regulation and achievement in a collaborative learning environment: the moderating effects of co-regulation and self-efficacy for group work. J Learner-Centered Curric Instr 15: 685-707, 2005.

13. Jung HR, Son AR, Yun YJ, et al.: Study on self-development needs, job satisfaction, self-efficacy by general characteristics of dental hygienist. J Korea Converg Soc 6: 231-239, 2015. https://doi.org/10.15207/JKCS.2015.6.6.231

14. Lee SJ: A Study on the development of life-skills: communication, problem solving, and self-directed learning. Korean Educational Development Institute, Seoul, p.145, 2003.

15. Yoon J: A study on the critical thinking disposition of nursing students: focusing on a school applying integrated nursing curriculum. J Korean Nurs Admin Acad Soc 14: 159-166, 2008.

16. Alavi SB, McCormick J: The roles of perceived task interdependence and group members' interdependence in the development of collective efficacy in university student group contexts. Br J Educ Psychol 78(Pt 3): 375-394, 2008. https://doi.org/10.1348/000709907X240471

17. Kim JH, Hwang TY: Development of job performance assessment tool for dental hygienists. J Korean Soc Dent Hyg 13: 713-726, 2013. https://doi.org/10.13065/jksdh.2013.13.05.713 
18. Kim JH, Han SJ: The effect of self-leadership on organizational effectiveness and job performance in dental hygienist. J Korean Soc Dent Hyg 16: 1079-1092, 2016. https://doi.org/10.13065/jksdh.2016.16.06.1079

19. Lee JH, Kim YS: Awareness on 4th industrial revolution of dental hygienists for future medical convergence. J Korea Converg Soc 9: 131-139, 2018.

https://doi.org/10.15207/JKCS.2018.9.10.131

20. Park EH, Kim HS, Kim JO: The effect of convergence action learning techniques in simulation class. J Korea Converg Soc 6: 241-248, 2015.
https://doi.org/10.15207/JKCS.2015.6.5.241

21. Yoo JB, Hong MJ, De Gagne JC: Factors affecting clinical competency of Korean nurses in the perianesthesia setting. $\mathrm{J}$ Korean Data Anal Soc 19: 3345-3359, 2017.

22. Cho HE, Moon IB: The effects of job satisfaction by the optimism, self-efficacy and job stresses of dental hygienists. Korean Public Health Res 40: 121-132, 2014.

23. Kim HY, Choi JO, Seong MG: The effect of self-efficacy and job satisfaction of Dental Hygienists'on the organizational commitment and turnover intention. J Korean Soc Dent Hyg 12: 213-223, 2012. 